Jurnal Konstruksi Hukum | ISSN: XXXX | E-ISSN: XXXX

Vol. 1, No. 2, Oktober 2020, Hal. 266-270| Available Online at https://www.ejournal.warmadewa.ac.id/index.php/jukonhum

DOI: https://doi.org/10.22225/jkh.1.2.2591.266-270

\title{
PERLINDUNGAN HUKUM TERHADAP KORBAN PENIPUAN JUAL BELI ONLINE
}

\author{
Bagus Andi Dwi Prakoso, I Nyoman Sujana, Luh Putu Suryani \\ Fakultas Hukum Universitas Warmadewa, Denpasar-Bali, Indonesia
}

\begin{abstract}
Abstrak
Saat ini media internet sering digunakan sebagai sarana berdagang di Indonesia yang acapkali menimbulkan aksi kejahatan cybercrime dari aksi kejahatan pengecohan dalam mendagang hingga objek penipuan jual beli online membutuhkan preservasi hukum. Bagaimana bentuk preservasi hukum terhadap objek pengecohan dalam mendagang online? Bagaimana sanksi pidana kepada pelaku pengecohan menggandar online? Dua pertanyaan ini adalah masalah yang dikaji dalam penelitian ini. Penelitian ini didesain menggunakan desain penelitian hukum normatif. Hasil penelitian dan pengkajian dapat disimpulkan bahwasanya parlindungan hukum bagi korban tindak pidana penipuan jual beli online pada hakikatnya dilakukan dengan jalur non-penal dan penal. Perlindungan hukum dengan jalur penal bisa direalisasikan melalui tindakan represif, dan non-penal melalui tindakan preventif. Dalam tindakan represif objek bisa dilaporkan dengan cara mendatangi instansi-instansi hukum untuk pemrosesan lebih dalam. Dalam tindakan praventif, penyuluhan diadakan tentang perundang-undangan dan pemahaman hukum tentang cara dan budaya pemakaian teknologi agar tidak ada respon terhadap permintaan informasi melalui $e$-mail. Hal-hal yang berpengaruh terhadap perlindungan hukum bagi korban penipuan jual buli online tertuju terhadap sedikitnya sarana dan prasarana sarana yang layak ialah belum maksimalnya penyuluhan peraturan perundang-undangan yang berhubungan dengan tindak pidana cybercrime kepada masyarakat. Kualitas aparat penegak hukum dan budaya masyarakat yang tidak tertarik untuk membuat laporan dan kesaksian. Pengecohan dalam mendagang dengan media online dalam ruang lingkup aturan hukum sudah diatur menggunakan hukum positif di Indonesia yaitu di dalam KUHP dan Undang-undang Informasi dan Teknologi Elektronik (UU ITE). Walaupun UU tersebut belum mampu menjera semua pelaku yang bersangkutan, namun melihat Asas Legalitas dalam Pasal 1 KUHP dan pendapat para ahli pidana perbuatan pengecohan berdangang online adalah suatu tindak pidana, dan oleh karena itu pasti melawan hukum. Maka harus dimintai pertanggung jawaban atas perbuatan ketika dilakukan.
\end{abstract}

Kata Kunci: Preservasi Hukum; Objek Pengecohan; Menggandar Online

\section{Abstract}

Currently, the internet is often used as a means of trading in Indonesia, which often leads to cybercrime crimes, from fraud in trading to fraudulent objects of buying and selling online, requiring legal preservation. What is the form of legal preservation of the object of fraud in online trading? How do criminal sanctions for fraudsters roll out online? These two questions are the problems examined in this study. This study was designed using a normative legal research design. The results of research and assessment can be concluded that legal protection for victims of online buying and selling fraud is essentially carried out by non-penal and penal channels. Legal protection using the penal line can be realized through repressive measures, and non-penal through preventive measures. In repressive actions, objects can be reported by visiting legal institutions for further processing. In a preventive measure, outreach is held about legislation and legal understanding of the ways and culture of using technology so that there is no response to requests for information via e-mail. Matters that affect legal protection for victims of online bladder selling are aimed at the lack of proper facilities and infrastructure, namely the inadequate extension of statutory regulations related to cybercrime to the public. Quality of law enforcement officers and the culture of the people who are not interested in making reports and testimonies. Fraud in trading with online media within the scope of legal regulations has been regulated using positive law in Indonesia, namely in the Criminal Code and the Electronic Information and Technology Law (UU ITE). Although the Law has not been able to deter all 
the perpetrators concerned, seeing the Principle of Legality in Article 1 of the Criminal Code and the opinion of criminal experts that online defamation is a crime, and therefore it is definitely against the law. Then it must be held accountable for the actions when it is done.

\section{Keywords: Preservation of Law; Fraud in Trading; Online leaning}

\section{PENDAHULUAN}

Negara Republik Indonesia merupakan negara hukum yang berlandaskan Pancasila dan UUD 1945, di mana Pasal 1 Ayat (3) UUD 1945 sebagaimana yang tercantum menyatakan: NKRI (Negara Kesatuan Republik Indonesia) merupakan Negara Hukum, atau dengan kata lain bahwa kekuasaan NKRI dijalankan berdasarkan ketentuan hukum yang berlaku di Indonesia bagi seluruh kehidupan telah diatur dengan hukum yang disahkan agar dapat melakukan pencegahan terhadap benturan yang terjadi diantara Masyarakat.

Sebuah negara Hukum Menurut Friedrich Julius Stahi dalam bukunya Asshiddiqie (2005) yang berjudul, "Konstitusi dan Konstitusionalisme Indonesia", setidaknya mempunyai empat unsur pokok, di antaranya:

a. Adanya pengakuan dan preservasi HAM;

b. Negara berdasarkan pada teori Trias Politica;

c. Pemerintahan berdasarkan pada UU (wetmatig bestuur);

d. Adanya peradilan administrasi negara yang memiliki tugas untuk menangani kasus perbuatan melanggar hukum oleh pemerintah (Onrechtmatige Overheidsdaad).

Di Indonesia sendiri teknologi informasi saat ini telah berkembang sangat pesat yang kemudian membawa pengaruh yang sangat besar terhadap bidang perekonomian (Barkatullah, 2005). Pemanfaatan teknologi informasi khususnya melalui media internet telah memberikan banyak manfaat terhadap berbagai aspek kehidupan masyarakat. Hal ini kemudian memicu lahirnya perdagangan secara elektronik (e-commerce). Akibatnya toko online (online shop) menjadi perhatian bagi masyarakat luas. Namun adanya online shop tidak terlepas dari dampak negatif yang salah satunya adalah pengecohan yang semakin hari semakin bertambah jumlah objek tersebut. Berdasarkan UU No. 31 Tahun 2014 pengganti UU No. 13 Tahun 2006 mengenai Perlindungan Saksi dan Objek, UU No. 11 Tahun 2008 mengenai Informasi dan Transaksi Elektronik dan UU No. 8 Tahun 1999 tentang Perlindungan Konsumen dapat disimpulkan bahwa perbuatan yang dilakukan oleh pelaku tindak pidana pengecohan menggandar online yang dilakukan melalui jaringan internet dapat dikenakan Pasal 62 Ayat (1) dan (2) Undang Undang No. 8 Tahun 1999 tentang Preservasi Konsumen, pasal 378 Kitab Undang-Undang Hukum Pidana (KUHP), pasal 28 ayat (1) dan Pasal 45 Ayat (2) Undang Undang No. 11 Tahun 2008 tentang Informasi dan Transaksi Elektronik karena tindak pidana yang dilakukan melalui jaringan internet mmenuhi unsur-unsur dari pasal tersebut.

Perkembangan teknologi informasi ini telah mengubah perilaku masyarakat dunia. Selain itu perkembangan teknologi informasi sudah membuat kehidupan menjadi tak terbatas (borderless) sehingga mengakibatkan perkembangan sosial secara khusus berjalan dengan cepat (Oetomo, 2002). Dikatakan saat ini teknologi informasi telah seperti pisau bermata dua mata, selain dikarenakan memberikan bantuan akan perkembangan kemajuan, kesejahteraan, dan kemakmuran kehidupan manusia, juga mengefektifitaskan terjadinya perbuatan yang melanggar aturan. Perbuatan melanggar aturan tersebut menjadikan ruang lingkup aturan harus diperluas agar mampu menjerat perbuatan tersebut. Cepatnya pertumbuhan teknologi komunikasi saat ini, terutama jaringan internet mengakibatkan munculnya kejahatan baru dalam bidang tersebut, seperti sabotase, spionase, money laudering, provokasi, pencurian software, hacking, kejahatan manipulasi data, perusakan hardware dan lainnya.

Aktifitas menggandar melalui media online dikenal dengan istilah electronic commerce atau $e$ commerce. E-Commerce adalah proses perdagangan melalui media online. Perdagangan melalui media online dapat mengefektifkan dan mengefesiensikan waktu hingga seseorang dapat melakukan aktifitas perdagangan kapan dan di manapun (Chaerudin, 2004). Aktifitas perdagangan melalui media online dilakukan tanpa harus bertemu antara para pihak; mereka melandaskan aktifitas transaksinya dengan rasa saling percaya antara keduanya, hingga transaksi e-commerce yang terjadi dilakukan secara online. Maraknya transaksi menggandar yang dilakukan oleh masyarakat melalui internet seakan sudah menjadi kebutuhan primer bagi masyarakat khususnya di daerah perkotaan. Dalam penerapannya 
perdagangan melalui media online telah memberikan dampak positif bagi masyarakat namun di sisi lain mempunyai kekurangan dalam transaksi menggandar online, karena pihak yang bersangkutan tidak dipertemukan secara langsung dengan pembeli. Tata cara dalam menggandar online ialah pihak yang membeli terlebih dahulu harus mentransfer sejumlah uang yang meliputi ongkos kirim, pajak dan harga barang, setelah penjual mengecek bukti pembayaran tersebut barulah penjual akan mengirimkan barang yang sudah dipesan dan dibayar oleh pembeli. Tata cara itulah yang menjadi kesempatan bagi oknum yang ingin mengambil keuntungan demi kepentingan sendiri yaitu dengan cara melakukan tindakan pengecohan, karena semua orang dari segala usia dan kalangan dapat menggunakan dan mendaftar di media sosial dengan sangat mudah.

Berdasarkan uraian di atas, isu yang dikaji dalam penelitian ini ialah bagaimana bentuk preservasi hukum terhadap objek pengecohan dalam menggandar online? Bagaimana sanksi pidana yang dijatuhkan kepada pelaku tindak pidana pengecohan menggandar online? Tujuan dilakukannya penelitian ini ialah supaya mengetahui lebih dalam tentang pengaturan hukum di Indonesia terkait dengan pengecohan menggandar online. Untuk mengidentifikasi, mendeskripsikan, dan menganalisis pengaturan hukum tentang preservasi hukum bagi objek pengecohan menggandar online.

\section{METODE PENELITIAN}

Tata cara penelitian ini dilakukan dengan tipe penelitian hukum normatif dengan pendekatan perundang-undangan serta konseptual dan dengan menggunakan teknik pencatatan. Pengumpulan data ialah berupa mengutip, meringkas, serta memberikan ulasan terhadap bahan-bahan hukum yang telah dikumpulkan yang kemudian dianalisa dengan merekontruksi norma menggunakan logika hukum deduktif dan induktif.

\section{HASIL DAN PEMBAHASAN}

PreservasiHukum ialah seluruh usaha pemberian hak dan bantuan agar mendapatkan rasa aman terhadap saksi/ objek, PreservasiMasyarakat melalui PreservasiHukum bagi objek kejahatan bisa dengan beberapa hal, seperti dengan pemberian kompensasi, restitusi, bantuan hukum dan pelayanan medis (Maskun, 2013). Subyek hukum yang diberikan preservasihukum baik yang bersifat represif dan yang bersifat preventif, baik yang tertulis dan yang lisan. Dapat dikatakan bahwasanya preservasihukum ialah suatu bayangan dari fungsi hukum, dimana mempunyai prinsip bahwasanya hukum menjadikan landasan ketertiban, keadilan, kedamaian, kemanfaatan dan kepastian.

Kemanfaatan, kepastian dan keadilan adalah buah dari bekerjanya fungsi hukum yang menjadi gambaran dari preservasihukum. Suatu hak yang diberikan kepada subyek hukum dan sesuai dengan aturan merupakan definisi dari perlindungn hukum, baik yang bersifat represif (pemaksaan) juga dalam bentuk yang bersifat preventif (pencegahan). Secara tidak tertulis maupun tertulis dalam menegakkan keadilan (Hadjon, 1987).

Tidak hanya KUHP yang memuat aturan tentang pengecohan namun ada aturan lain yang dengan prinsip mengatur tentang kejahatan cybercrime yaitu UU No. 11 Tahun 2008 tentang informasi dan transaksi elektronik (UU ITE), UU ini sudah dikaji tentang faktor-faktor yang berhubungan dengan informasi dan transaksi elektronik sertatentang hal-hal dilarang yang berhubungan akan "dunia maya" disertai ancaman hukumannya. UU ITE sendiri tidak menyatakan dengan sepenuhnya mengenai makna pengecohan, namun untuk pengecohan menggandar online dapat kita lihat didalam Pasal yang terdapat dalam Undang undang ITE, seperti pasal 28 ayat (1) Undang undang ITE dan dikuatkan dengan terpenuhinya unsur unsur pidana. Tidak ada aturan dalam Pasal 28 ayat (1) Undang undang ITE yang mengatur secara terperinci tentang kejahatan pengecohan akan tetapi berhubungan akan adanya konsumen yang rugi mengatakan:

"Secara tanpa hak melakukan penyebaran berita bohong dan menyesatkan yang menimbulkan

kerugian bagi konsumen didalam melakukan transaksi elektronik."

Ungkapan berita bohong \& menyesatkan dalam Pasal 28 Ayat (1) Undang-Undang ITE bisa disamakan ungkapan tipu muslihat atau rangkaian kebohongan seperti unsur unsur yang dimuat dalam Pasal 378 KUHP. Bisa dikatakan bahwasanya Pasal 28 Ayat (1) Undang-Undang ITE adalah perkembangan dari kejahatan pengecohan dengan cara konvensional, atau kejahatan pengecohan yang biasa dialami dalam kehidupan masyarakat.

Pengecohan ialah serangkaian perkataan bohong yang disengaja dan ditekankan sampai membuat seseorang merasa perkataan tersebut seakan benar. Pengecohan yang dilakukan oleh seseorng biasanya 
menjelaskan suatu hal seperti seakan-akan benar/fakta, padahal perkataan tersebut jauh dari kenyataan, sebab Tujuannya hanyalah meyakinkan target incarannya lalu menggunakan identitas palsu agar tidak ada yang mengetahui identitas pelaku, sama halnya seperti jabatan palsu supaya target percaya dengan apa yang diucapkannya. Menipu dalam kehidupan masyarakat ialah tindakan yang buruk akan tetapi pelaku tindak kejahatan tersebut jarang dilaporkan ke aparat penegak hukum. Menipu berskala ringan yang tidak dilaporkan menjadikan Pelaku kejahatan pengecohan meluaskan pergerakannya sehingga lama-kelamaan menjadikannya pelaku pengecohan yang berskala besar.

Walaupun Undang-undang ITE telah menjelaskan peraturan tentang problematika yang berpotensi dalam perdagangan dengan media online, tapi tidak akan dapat diselesaikan hanya dengan Undang undang ITE saja. Sampai sekarang, metode pengaduan bagi objek belum dimaksimalkan. Hingga saat ini hanya mengandalkan metode pengaduan yang terdapat pada KUHAP (Kitab Undang-Undang Hukum Acara Pidana). Metode ini dilihat kurang tepat kalau diaplikasikan dalam tata cara pengaduan perdagangan online. Kecilnya nilai transaksi yang menjadi pertimbangan bagi objek dalam melaporkan kerugian kepada pihak yang berwajib. Didukung dengan adanya dugaan bahwa biaya pelporan akan lebih besar dari kerugin yng dialami. Maka dari itu dibutuhkan suatu sistem pengaduan yang mampu bekerja lebih efisien dan efektif. Akan sangat membantu apabila aparat penegak hukum mampu memberikan daftar hitam (blacklist) bagi pelaku pengecohan dalam perdagangan media online yng telah terbukti merugikan masyarakat.

Yang membedakan pengecohan secara online dengan pengecohan konvensional hanyalah sarananya, di mana pelaku pengecohan secara online menggunakan perangkat elektronik seperti smartphone dan komputer untuk melakukan aksinya (Raharjo, 2002). Oleh karena itu, hukuman bagi pelaku penipuan secara online diberlakukan sama dengan pelaku pengecohan konvensional di mana telah diatur dalam Kitab Undang-Undang Hukum Pidana (KUHP). Sebagaimana yang dinyatakan dalam Pasal 378 KUHP, yang menyatakan:

"Orang yang dengan sengaja atau tanpa sengaja bermaksud menguntungkan dirinya atas cara mengecoh orang lain akan diancam karena melakukan pengecohan dengan sanksi penjara paling lama 4 tahun."

Namun jika dilihat dengan Undang-Undang No. 11 Tahun 2008 tentang Informasi dan Transaksi Elektronik (UU ITE), akan dikenakan Pasal 28 Ayat (1), yang menyatakan:

"Setiap orang dengan sengaja melakukan pengecohan terhadap pembeli pada transaksi online yang mengakibatkan adanya kerugian."

Dengan ancaman pidana berupa penjara paling lama 6 (enam) tahun atau denda paling banyak 1 miliar (Pasal 45 Ayat (2) UU ITE). Dengan pembuktian menggunakan bukti elektronik/ hasil cetakannya untuk perluasan bukti seperti Pasal 5 Ayat (2) Undang-Undang ITE selain bukti lain yang sesuai dengan Kitab Undang-Undang Hukum Acara Pidana (KUHAP). Pasal 5 UU ITE menyatakan:

(1) Informasi Elektronik dan/ atau Dokumen Elektronik dan/atau hasil cetaknya merupakan alat bukti hukum yang sah.

(2) Infarmasi Elaktronik dun/ ateu Dokuman Elektranik dun/ ateu hasal ceteknya sebagaimona dimaksed peda ayat (1) merapakan perluasen duri alet bakti jang tsah sesoai dengen Hukom Acare jang berlaka di Indunesia.

\section{SIMPULAN DAN SARAN \\ Simpulan}

Mengenai bentuk preservasi hukum mengenai pengecohan transaksi menggandar online, terutama dalam hal kebijakan yang dapat diterapkan pada pelaku, Kitab Undang-Undang Hukum Pidana (KUHP) dan UU ITE seperti peraturan perundang-undangan yang berlaku di Indonesia mengenai tindak pidana ini, masing-masing telah diatur dalam satu pasal, yaitu Pasal 378 KUHP dan Pasal 28 Ayat 1 UndangUndang ITE. Sanksi pidana bagi pelaku Tindak Pidana Pengecohan Menggandar online sebagaimana yang tercantum dalam Pasal 378 KUHP yaitu berupa ancaman penjara paling lama 4 (empat) tahun. Sedangkan, jika dijerat menggunakan Undang-Undang No. 11 Tahun 2008 tentang Informasi dan Transaksi Elektronik (UU ITE), maka pasal yang dikenakan adalah Pasal 28 Ayat (1) di mana ancamannya berupa penjara paling lama 6 (enam) tahun dan/ atau denda paling banyak 1 miliar. 


\section{Saran}

Berdasarkan hasil penelitian dan diskusi yang telah diuraikan, bebera saran kepada beberapa pihak diberikan seperti berikut:

1. Bagi pemerintah

a) Meningkatkan prioritas nasional dalam menangani kejahatan melalui media online seperti membuat satuan khusus dalam cybercrime yang khusus menangani masalah pada dunia maya terutama dalam kasus pengecohan menggandar online.

b) Aparat penegak hukum dengan instansi-instansi terkait melakukan kerja sama untuk melakukan sosialisasi dan penyuluhan tentang bahaya tindak pidana cybercrime, terlebih mengenai pengecohan yang dilakukan secara online dan mensosialisasikan Undang-Undang Informasi dan Transaksi Elektronik sebagai upaya preventif agar masyarakat mengetahui bagaimana akibat jika terjadi pelanggara terhadap informasi dan transaksi elektronik.

2. Bagi masyarakat

Masyarakat harus lebih cermat dan berhati-hati melihat apakah informasi tersebut benar atau tidak, serta lebih memahami melalui pembelajaran internet tentang cybercrime khususnya pengecohan yang dilakukan secara online dan diharapkan kesadaran masyarakat secara langsung untuk melaporkan kepada pihak kepolisian apabila ada hal yang patut dicurigai merupakan tindak pidana pengecohan secara online.

\section{DAFTAR PUSTAKA}

Asshiddiqie, J. (2005). Konstitusi dan Konstitusionalisme Indonesia. Konstitusi Press.

Barkatullah, A. H. (2005). Bisnis E-commerce: Studi Sistem Keamanan dan Hukum di Indonesia. Pustaka Pelajar. Chaerudin. (2004). Korban Kejahatan dalam Perspektif Viktimologi \& Hukum Pidana Islam. Grhadhika Press.

Hadjon, P. M. (1987). Perlindungan Hukum Bagi Rakyat di Indonesia: Sebuah Studi tentang Prinsip-Prinsipnya, Penanganannya oleh Pengadilan dalam Lingkungan Peradilan Umum dan Pembentukan Peradilan Administrasi Negara. Bina Ilmu.

Maskun. (2013). Kejahatan Siber (Cyber Crime) Suatu Pengantar. Kencana.

Oetomo, B. S. D. (2002). e-Education: Konsep, Teknologi dan Aplikasi Internet Pendidikan (1st ed.). Andi.

Raharjo, A. (2002). Cybercrime: Pemahaman dan Upaya Pencegahan Kejahatan Berteknologi. Publisher. 